\title{
Bioclimatic Architecture
}

\author{
Jimena Ávalos ${ }^{1}$, Regina Villarreal ${ }^{2}$, Valeria Cárdenas $^{3}$, Ana Cristina García-Luna Romero ${ }^{4}$ \\ ${ }^{1}$ UDEM, Universidad de Monterrey, Zona Valle Poniente, 66238 San Pedro Garza García, N.L. \\ ${ }^{2}$ UDEM, Universidad de Monterrey, Zona Valle Poniente, 66238 San Pedro Garza García, N.L. \\ ${ }^{3}$ UDEM, Universidad de Monterrey, Zona Valle Poniente, 66238 San Pedro Garza García, N.L. \\ ${ }^{4}$ UDEM, Universidad de Monterrey, Zona Valle Poniente, 66238 San Pedro Garza García, N.L.
}

\begin{abstract}
We are living through serious problems of environmental pollution, which causes great risks to the well-being of the population. These problems are presented by the bad planning of urban growth, and many times in very bad quality. Industrialization grows in the cities without having an order and an appropriate planning to avoid the damage in our environment. The construction sector is largely responsible for this global pollution that is experienced today. As the years go by, architects aim to improve the quality of their construction and improve our quality of life. New projects arise with strategy and planning, developing a new type of architecture which contemplates the damage it would do to the environment and how this issue could be solved based on its construction development. The profession of architects, or urban planners who are involved in the development of cities, are responsible for creating new developments by designing the impact of climate change. The architectural community carries a great responsibility in designing with the flows of materials, energy, climate change, causes and solutions in mind. Architecture must involve sustainability in its construction process and know how to implement it to cause an environmental impact to satisfy the common welfare.
\end{abstract}




\subsubsection{How Architecture Harms the Environment}

We are experiencing climate change in our planet, which causes heat waves, increase of hurricanes, reduction of the ice surface, coastal invasions, loss of biodiversity, and loss of drinking water, etc. Greenhouse gases are being created in the atmosphere which are caused by human activity. Important data to analyse this problem is that the Energy Information System of the United States indicates that the buildings are those that damage the environment by their total emissions of greenhouse gases that impact the environment in a negative way. The energy consumption by sector can be seen $48 \%$ in buildings, $25 \%$ in industries and $27 \%$ in transport [1]. Due to this analysis it is possible to report that the influence of construction and architecture has an impact in what is global warming. Architecture has an influence on the environment related to energy consumption, due to its use as heating, air conditioning, and lighting. The architectural process has a high impact on the ecological sector. That is why architecture has a high responsibility for how it is planned, projected and built based on how it could contribute and not damage the ecological sector [2]. The architectural design can contain compositional strategies which reduce risks to the environment, and which are capable of contributing to biodiversity. Architecture has a great impact on the environment, and it is possible to analyse how with the years, natural resources deteriorate and global warming increases. In recent years there have been very extreme climate changes, and it is now faster and more geographically extensive than any change in the last two millennia [1]. Over the last century, global warming has caused several natural disasters, seasonal changes, and water supply problems. These events mentioned are just a few of the many disasters that could happen in the future as a consequence if no quick action is taken. We have seen scenarios in the last 25 years of how the sea level has doubled, precipitation risking pollution of drinking water, extreme weather events, global temperature increasing, countries generating tons of carbon dioxide, disappearance of flora and fauna, etc [1]. All these phenomena arise from the deterioration of natural resources and the bad use of them, causing a strong impact in the environment. This occurs from the excessive consumption of natural resources that are gradually deteriorating. Architecture has a great role in the environment not only because it consumes natural resources, but also because it occupies a space that can be put to good use, or simply damaged around it. Environmental deterioration is increasing since the cities are growing with development and planning without order nor strategy, of which proposals are raised that only harm the cities and the urban development. Over the years, these problems began to grow exponentially, which began to raise laws and standards of conservation in cities and laws that raise the need for sustainable design developments within cities [3].

\subsubsection{How Architecture Promotes Pollution Relief}

Since architecture has a great impact on pollution, solutions began to be proposed to minimize these energy consumption effects of buildings. There is a growing awareness in the architectural sector to create a positive impact on the environment. It was decided to build passive buildings, which do not require much energy consumption and are designed to have renewable energies. In big cities there is a great deterioration of natural resources, and 
pollution is increasing exponentially. Architecture evolved as a result of this problem and reference began to be made to constructions committed to the care of the environment.

In order to achieve this, the concept of sustainable architecture was created, which fulfils fundamentals that are oriented to be catalogued as ecological. A great example of this would be the passive houses and how they are made to have a control in the use of gas, oil and electricity. These passive houses have materials which have properties to avoid the emission of polluting gases. This type of building does not require much electrical energy and significantly reduces gas emissions into the environment. Passive houses are a research study for architects who implement sustainability in their constructions and are able to design using the outside environment to produce benefits and contribute instead of polluting. Concluding this point, the design of these houses are aimed at having adequate insulation, no air leaks, thermal materials, quality windows, adequate ventilation, etc. All these characteristics are guided by a sustainable and adequate design to promote and make sustainable architecture a reality [4].

A new modality was chosen to seek the integration of sustainability in construction. Several certifications were created to be able to have green " building evaluations through design guidelines and parameters focused on sustainability. These buildings "greens " could be reflected for the first time in 1987 created by the World Commission on Environment and Development of the United Nations. It was created in 1987 , but began to be reflected throughout the world in 1992. These were years in which new ideologies were raised in architecture, leaving behind bad practices and bad uses of projects that polluted and caused damage. A method of LEED certification was created, which is applicable to projects that follow these guidelines and parameters in their design and focus on energy use, water use, and waste [5].

LEED certification stands for Leadership in Energy and Environmental Design. LEED is a certification system that was created in 1993 in the United States. This system is composed of several standards for cataloging energy efficiency in buildings. The objective of this system is that the buildings develop in its project the part of energy efficiency and is in walk to the sustainable thing. When some project obtains this certification, it means that it is a project of which it has an environmental quality in its interior and an efficiency of water consumption. This certification is composed of different areas of which can be within the following: sustainable sites, water saving, energy and atmosphere, materials and resources and indoor environmental quality. The buildings are scored based on which category supports your project and on what its use is focused. LEED certification not only goes to the building market, but also can certify new construction, existing buildings, housing, neighbourhoods, and finally educational institutions. In Latin America this certification has been growing exponentially in the amount of buildings with LEED certification. There are more and more buildings with sustainability issues and it is something that architects today seek to improve the quality of their projects and achieve this certification [5]. 
There is another certification called GBCE- GREEN, which is an organization that also has an evaluation protocol for buildings that consider sustainability and established criteria in their construction. The advances of the industrial revolutions caused the opening of new materials in their respective moment, thus the sustainable architecture was born after several revolutions and several methods of which nowadays are not enough for the society and the environment [6].

\subsubsection{What is Sustainable Architecture and how does it relate to our theme?}

To catalogue a certain sustainable architecture it would be necessary that it meets the needs without compromising the ability to harm its own needs. The word sustainability goes beyond the reaction it makes to the environment, but it is a concept that has the capacity to endure. For this term to be valid, that is to say, to be feasible, biological systems need to remain productive over time, and be contemplated in the long term. This example can be seen in forests because they have a sustainable biological system that lasts for many years. By focusing more on humanity, this concept of sustainability creates a well-being and the common good of human health in the long term. Sustainability interacts with environmental, economic and social issues. This concept contributes to different areas which create social and ecological consequences in human activity. Sustainability, as mentioned, involves various aspects of human life, which need to be put into practice in the field of architecture because it is what causes us the greatest impact as human beings [4].

This concept could be divided into three fundamental concepts: the development of the use of raw materials and renewable energies, the analysis of the life cycle of materials, and the reduction of materials and energy used on the basis of natural resources [7]. These concepts are indispensable for cataloging architecture as sustainable and as a concept with environmental awareness that does not harm the environment. Encompassing all these issues, sustainable architecture today is a necessity for our environment and for our daily lives, and is even already a trend and business for the future. This new evolution proposes new things that people want to be part of this movement, in order to put a stop to global warming. Developing this new stage that is being lived, we began to see case studies as in Argentina that began to implement solar panels and stainless steel on the facades of buildings. With this, what was achieved was to save architectural and energy materials. It was a system implemented to capture solar energy in the building's facade. Another example that developed sustainable architecture was in the United States. In the tower "Hearst Tower", a system was implemented for energy consumption and a water circulation system that allows heating in winter and cooling in summer. Likewise, more designs were implemented that allow for the recycling of rainwater to have different uses with that water within the building. All these new trends began to spread around the world, due to the deterioration of natural resources in the world. 


\subsubsection{Developing the world's sustainability strategy - What are we doing to fight this problem?}

There is an initiative of General Directors (CEO's) of the organizations that have signed the United Nations Global Compact who implement the universal principles of sustainability and take action to achieve the development of sustainable foundations in cities. A global forum was formed in 1999, with business leaders elected for this work to create a global pact of values and principles to develop sustainability and to be fulfilled as such. This global compact goes hand in hand with the United Nations and they work together to create this message to the world, which is needed to start seeing changes within human life [8]. This forum aims to consolidate sustainability strategies and social responsibility. Businesspeople are formulating cross-cutting measures and designs that architecture can support in order to fulfil this purpose of sustainability, within which we can catalogue a certain branch such as bioarchitecture. Examples of measures carried out by this forum are, for example, the generation of energy, based on domestic installations that have renewable sources of energy using solar panels [8]. Another measure that is promoted within this movement that fights pollution is the strategy of generating clean energy [9]. Greater importance is being given to natural gas than its amount of carbon dioxide that it releases is a very small proportion of which is not so harmful to the environment. Another important aspect that the forum mentioned is to have clean and renewable energies such as wind, hydro and solar energy. All these concepts are based on solutions to combat this pollution that is already caused by the misuse of natural resources which are being depleted [10]. These actions are the ones that lead to what have been branches of sustainability implemented in architecture. One of them, as already mentioned, is bio-architecture.

Architect Sebastian Ortega, who specializes in constructions and natural techniques or bio-constructions, talks a lot about the subject of bio-architecture. The architect mentions that the parameters of bio-architecture can be applied to the areas of regional construction that use measures to protect the environment. Bio-architecture is a field that comes from bioclimatic architecture that has been in the architectural records for many years. There were many analyses of the area of sunshine, solar angles and sciences, dominant winds, etc. In the last centuries, the industrialized construction was losing all these concepts that form as a whole measures that help for our environment and in the end fall in what harms the environment [12].

Another support forum to combat this problem was created in the 1980s by the United Nations Brundtland Commission on March 20, 1987. Since the 1980s, sustainability has been of great importance to human beings, and this concept has been greatly promoted. The Brundtland Commission issued a publication in the 1980s indicating how sustainability involves all aspects of human life. Because of this and many other valuable sources coming from important forums, the message they gave was to change a lifestyle so that something fundamental would be seen that would help human health in the long term. Because of this 
new way of thinking, architecture was put into practice by contemplating this concept of sustainability. In 1993, a group from the International Union of Architects catalogued certain buildings as sustainable, and from then on a Sustainable Future was contemplated within architecture, based on the three areas already mentioned: social, economic, and environmental [13].

Like the architect Pablo Capitanelli suggests that bio-architecture is not only ecological and what we know how to recycle, but is to seek a healthy architecture with the best conditions for the health of people who live in the house. In terms of construction, it also has a contribution to bio architecture such as the carbon footprint that a building can have. To define that a project is supported by bioarchitecture, it has to be seen backwards and forwards. The architect defines backwards how to see all the processes of the production of the materials and how the project is going to be done. He mentions that the process of how a certain material came to contribute to the project, it is fundamental to see the analysis of production and what it took to get to be used in the end in the project. The architect mentions that what he refers to ahead is to analyse all the systems that are implemented in a project to save natural resources. It is fundamental to analyse all the expenses that imply a certain project in the future. The analysis to catalogue something sustainable is entire, from the beginning of the production of the material, until the end of the aging of the house [13]. A fundamental example for this concept would be a house made of clay, when it comes to destroying itself, instead of producing garbage or some element that is not functional, the point of this is that it produces earth in order to design something else with the material. This type of architecture seeks to implement natural materials, which reject steel, aluminum, and plastic, preferring to use wood and new breathable and ecological components.

Throughout history, concrete, steel, brick, and glass have been used to design large structures. These materials have left a mark on history in a negative aspect by forming carbon fibers and it is necessary to end this great threat. Another concept about bio architecture can be based on Neri Oxman. Neri Oxman is a woman who designs the relationship between building materials and the environment. What she achieves is to integrate art, design, science and engineering into her projects, with new types of materials. These materials are for, by, and with nature through the concept of bio-architecture. Neri Oxman carried out a project called "Agua Hoja" in New York, from which she designed a biocompatible structure made of natural materials [6]. Its objective is to search and find materials that replace plastic or any other material that is harmful to the environment. Neri Oxman demonstrated that there are different alternatives for building and manufacturing. She is based on the concept that these forms are based on nature, and in this way one could cohabit and co-manufacture in harmony. Neri's concept is based on the disciplines of art, science, design, and engineering so that together they form a balance between the theory of 
science and the sensory of nature by implementing bio architecture and thinking about the future by protecting nature [6].

As a conclusion on the subject of bio architecture, all this information will refer to an essential example in sustainable architecture, which is bio architecture. Bio-architecture comes from the connection between the earth and positive energies and how they are reflected in what architecture has been. Bioarchitecture's main function is to establish relationships between what is built and developed within projects, with the surroundings and the environment [9]. On this type of architecture, its constructive function is based on improving the quality of energy resources of the place, and generate a positive impact for the environment. It is the ecological construction that improves the city and nature of the world having in conscience the environmental thing. This branch of architecture is born from the bioclimatic architecture that focuses on each plot that harms the well-being of the human, for which it is decided to take actions and implement them to change this situation and cause a different sensation. This concept is born from the antiquity where natural materials were used like water, straw, clay, wood, stones, canes, branches, etc. The world in its first centuries tried to survive and build houses with materials without any energy, because these did not exist. Our ancestors lived from nature and what it gave them to have materials and survive with them. Likewise, bio-architecture transmits health even to people who live inside buildings that have this type of concept, it is proven by doctors in hospitals who have testimonies about their experience inside bio-architecture. Bio-architecture provides spaces in a responsible way for the environment and for the users. Bio Architecture gives life, and it is lived within it [13]. Leading the main function of this concept, it goes from the evaluation of the place to the materials that will be used to create a building with good functionality and efficiency in its use. They started to implement intelligent buildings which do not pollute and are based on energy resources in a sustainable way. Today, it reflects what is devastating us, so the goal of this type of architecture is to help nature regenerate everything that humans misused and is in danger [7].

\section{Study Case}

Currently, architects are focused on increasing the monetary value of their building, establish a predominant design in the city and build more, however what they should sustain is to improve the environment in which we live and create architectural features to give a use to nature, whether lighting, the movement of the sun, the prevailing winds, and may other different factors that will create a responsive skin where the building interacts with it and its environment.

This new architecture is really very scarce and is not implemented worldwide, however these few buildings are made in a very interesting way. One of them is located in Tlalpan within Mexico City, this building is of a general medical use called the Dr. Manuel 
Gea Gonzalez General Hospital, designed by a German architectural firm called Elegant Embellishments, who implement as their main mission "to reconcile technology and the environment through innovative construction products [14]. It is one of the largest in the center of the country and what stands out is its sustainability which eliminates smog from the city and uses natural energy. This building is located in Mexico City, and for this reason the architectural firm created an architectural space capable of neutralizing contaminating emissions through its facade. To do this, a new type of tile made of "Prosolve37oe" was used; this term is a decorative architectural module that significantly and effectively reduces air pollution in cities. The implemented modules are coated with superfine titanium dioxide, a technology that effectively combats pollution which is activated by daylight. Likewise, this module is implemented near the main roads or highways, since this model is capable of neutralizing the pollution produced by 8,750 cars daily [13]. All these characteristics that this building has created is within the concept of bioarchitecture. It is the first building in Mexico and Latin America that has a friendly technology in the façade to combat the polluting emissions caused by cars in the city. It is a design that was thought about the people around them, their future years and above all, how they can contribute something in their design for the environment. As these sustainable buildings with this same structure, the country only has this one, and in the world in general there are two similar ones. There is a similar building in London, which is a medical unit specialty tower and that is in charge and has the same use of reconciling technology and the environment. It achieves this through its innovative construction products, as does the General Hospital Dr. Manuel Gea Gonzalez.

The design of the facade in this building, apart from having complementary uses to sustainability, has a disruptive and highly decorative design. The architects in charge of this project are Allison Dring and Daniel Schwaag. These architects were the designers who managed to create the function of reducing emissions of polluting particles equivalent to about 1,000 cars a day. This statistic was achieved thanks to the titanium dioxide coating that this building has on its roof or architectural skin. The facade is the module that, besides being decorative, reduces all this air pollution caused by Mexico City, which is a city catalogued as one of the most polluted in the world. Speaking more in detail, the facade works on the basis of armed modules covered with a super-fine titanium dioxide, which fights pollution. By doing so, these modules neutralize air pollutants, and all this smog that is caused by traffic, these modules help reduce such scenarios [7].

The architect Antonio Medina explains that the installation of this façade was based on the hospital's southwest orientation. It was an installation designed to protect from sunlight, since this is the area that receives many sun rays throughout the day due to its location and orientation. This building is thought beyond the aesthetic, but has a double personality that is capable of providing a comfortable environment and that contributes to the environment as the facade does. Due to its orientation, the hospital conserves a regulated environment which allows natural light to enter its floors, and this makes it an experience different from any other, causing comfort [15]. 
How you can get to observe everything is thought beyond what is posed as the orientation or how the unique design of the facade. The architects designed everything with a purpose and always thinking about the comfort of the user, and above all the environment. Apart from having natural light, created by the design based on the orientation of the sun, this was designed to save a lot of energy. The architect Antonio Medina explains how the modules absorb the air pollutants that limit the passage to this building, and when it rains this facade gets rid of this. It is all a technology thought on the basis of these criteria that the architects decided to fight and to work them to extract a result of which it contributes and it does not harm our environment.

It was mentioned by the head of the maintenance area of the General Hospital Dr. Manuel Gea González, that this building placed this structure with these functions between the years 2011 and 2012. The structure has an exposed facade of 2,200 square meters, which was placed with the support of the company "Elegant Embellishments". The maintenance manager of the hospital mentions that it is a building which has to be treated every 10 years to give preventive maintenance to what has been the titanium roof to leave it preserved in good condition. After several interviews and several architects who mention this building as sustainable, the Angels Health Services Group was in charge of presenting the project and validating the structure that has these properties based on the environment. There are other structures in projects designed with this same use to remove smog from the city located in Australia and the United Arab Emirates [16].

\section{References}

1. Veka. (2020)

https://www.veka.es/como-impacta-la-arquitectura-en-el-medio-ambiente/

2. La Bioguía, (2020)

https://www.responsabilidadsocial.net/la-arquitectura-sustentable-concepto-principiosmitos/

3. Alto Nivel. (2010)

https://www.altonivel.com.mx/estilo-de-vida/arquitectura-sustentable-tendencia-verde

4. Enlight. (2020) https://residencial.enlight.mx/arquitectura-sustentable/

5. BLOG OFICIAL, Radio. (2020)

https://blognooficial.wordpress.com/author/blognooficial/

6. Arquitnepolis. (2020) https://arquinetpolis.com/certificacion-leed-000029/ 
7. P. Capitanelli, (2014) https://www.youtube.com/watch?v=aYFaVw8flDE

8. A. Herrera, INFOBAE. (2020)

https://www.infobae.com/america/mexico/2019/03/16/disruptivo-decorativo-y-sustenta ble-el-edificio-de-un-hospital-mexicano-que-come-smog-y-atrae-la-luz-solar/

9. H. Torres, (2020) https://www.youtube.com/watch?v=QTWbAYYaxso\&t=1s

10. COMPAC, The Decorative Surface. (2018) http://www.thedecorativesurfaces.com/bioarquitectura/

11. L. Zesati, (2013) https://www.youtube.com/watch?v=GnnSQIrd6tg

12. Pacto Global, (2020)

https://www.pactomundial.org.mx/que-es-el-pacto-mundial/?creative $=474214048950$

13. M. Luxán García, (1997) http://habitat.aq.upm.es/cs/p3/a019.html

14. Construye. (2020)

http://www.revistaconstruye.com.mx/noticias/2838-\%C2\%BFqu $\% \mathrm{C} 3 \% \mathrm{~A} 9$-es-la-bioarq

15. Local. (2020)

https://local.mx/ciudad-de-mexico/medio-ambiente/el-congreso-de-la-ciudad-de-mexic ol

16. VAD Producciones. (2020) https://www.youtube.com/watch?v=6Q_5ASLlOAg

17. De. Mx. (2016)

https://masdemx.com/2016/07/la-fachada-del-edificio-mexicano-que-come-smog-fotos / 